\title{
Immunogenicity and Efficacy Evaluation of Vero Cell-Adapted Infectious Bursal Disease Virus LC-75 Vaccine Strain
}

\author{
Wakjira Kebede' \\ Molalegne Bitew ${ }^{2}$ \\ Fufa Dawo Bari ${ }^{3}$ \\ Bedaso Mammo Edao ${ }^{3}$ \\ Hawa Mohammed' \\ Martha Yami' \\ Belayneh Getachew' \\ Takele Abayneh' \\ Esayas Gelaye'
}

'National Veterinary Institute, Bishoftu, Ethiopia; ${ }^{2}$ Ethiopian Biotechnology Institute, Addis Ababa, Ethiopia; ${ }^{3}$ College of Veterinary Medicine and Agriculture, Addis Ababa University, Bishoftu, Ethiopia
Correspondence: Esayas Gelaye National Veterinary Institute (NVI), PO Box: 19, Bishoftu, Ethiopia

$\mathrm{Tel}+25$ I 923625362

Fax +25 I I 4339300

Email esayasgelaye@gmail.com

Fufa Dawo Bari

College of Veterinary Medicine and

Agriculture, Addis Ababa University,

PO Box: 34, Bishoftu, Ethiopia

Tel +25I 929190312

$\mathrm{Fax}+25$ I II 4339933

Email fufa.dawo@aau.edu.et
Introduction: Infectious bursal disease virus (IBDV) is an avian viral pathogen that causes infectious bursal disease (IBD) of chickens. The disease has been endemic in Ethiopia since 2002, and vaccination has been practiced as the major means of disease prevention and control. An IBD vaccine is produced in Ethiopia using primary chicken embryo fibroblast (CEF) cell, which is time-consuming, laborious, and uneconomical. The present study was carried out to develop cell-based IBDV LC-75 vaccine using Vero cells and to evaluate the safety, immunogenicity and protection level.

Methods: Identity of the vaccine seed was confirmed with gene-specific primers using reverse transcription polymerase chain reaction (RT-PCR). Confluent monolayer of Vero cells was infected with vaccine virus and serial passage continued till passage 10. A characteristic virus-induced cytopathic effect (CPE) was observed starting from passage 2 on the third day post-infection. The infectious titer of adapted virus showed a linear increment along the passage level. The virus-induced specific antibody was determined using indirect ELISA after vaccination of chicks through ocular route.

Results: The antibody titer measured from Vero cells vaccinated chicks revealed similar level with the currently available CEF cell-based vaccine, hence no significant difference. Chicks vaccinated with Vero cell adapted virus showed complete protection against very virulent IBDV, while unvaccinated group had $60 \%$ morbidity and $25 \%$ mortality.

Conclusion: It is concluded that the IBDV vaccine strain well adapted on Vero cells and found to be immunogenic induces antibody development and successfully protects chicks against challenge with the circulating field IBDV isolate. Hence, it is recommended to produce IBD vaccine using Vero cell culture at the industrial scale to conquer the limitations caused by using CEF cells and thus to vaccinate chicks population to protect against the circulating IBDV infection.

Keywords: antibody, chicks, IBD vaccine, immunogenicity, protection, Vero cell

\section{Introduction}

Infectious bursal disease (IBD), also known as Gumboro, is an immunosuppressive disease of chickens and is the second priority chicken disease in Ethiopia, next to Newcastle disease, that needs to be controlled primarily through vaccination. ${ }^{1}$ The etiological agent is IBD virus (IBDV) which belongs to the family Birnaviridae, $a$ is a non-enveloped, double-stranded and bi-segmented ribonucleic acid (RNA) genome. ${ }^{2}$

The majority of chicken production in Ethiopia is managed under a small scale backyard management system which serves as a source of protein food and generates a 
cash income. In 2019/20, Ethiopia had an estimated poultry population of around 56.99 million. ${ }^{3}$ IBD was first reported in Ethiopia in 2002 at commercial poultry farm in which a $45-50 \%$ mortality rate was reported. ${ }^{4}$ Subsequently, IBD has become a second priority problem next to Newcastle disease in both commercial and backyard poultry production systems in Ethiopia, despite regular vaccination practices using IBDV LC-75 vaccine and improved biosecurity measures. ${ }^{5}$ Since then, the circulation of very virulent and/or classical virulent IBD viruses were reported from different parts of Ethiopia. ${ }^{6,7}$

Vaccination is the cheapest, most practical and economical method of disease control globally. Mostly disease control strategies designed in Ethiopia do not consider the local chickens reared under the backyard management, which contributes to the majority of the chicken population. Despite improved chicken genotypes being distributed to smallholder farmers in the country by different organizations as a means of improving the livelihood of the chicken owners, these development activities failed because of the presence of priority endemic poultry diseases like IBD. Previous report indicated that chicken vaccination against prevailing diseases in Ethiopia did not take into account local chicken populations found under smallhold farmers' management conditions. ${ }^{8}$

Since 2004, highly pathogenic IBDV strains have emerged through mutation and genetic re-assortment. ${ }^{9}$ IBD is a contagious and economically important poultry disease in Ethiopia where the disease created severe morbidity, production loss and mortality. ${ }^{10}$ Unless the chicks get vaccinated between 2 and 6 weeks of age, it can lead to considerable economic loss. Therefore, vaccination is considered as an important means of protecting birds during their first weeks of life. ${ }^{11}$ One of the strategies to prevent and control IBD is to hyper-immunize breeders with vaccines. ${ }^{12}$ Although passive immunity promotes good protection of chicks during the first weeks of life, permanent protection against IBD requires the vaccination using live vaccines. ${ }^{13}$ The live IBD vaccines so far developed and in use are categorized as "mild", "intermediate" and "hot" according to their degree of virulence. ${ }^{14}$ Mild vaccines are safe for specific pathogen-free (SPF) chickens but are not very effective in the presence of high level maternal antibodies or against very virulent strains of IBDV. Hence, the intermediate and hot vaccines are much more effective but may induce moderate to severe lesions in the Bursa of Fabricius of vaccinated chicks. ${ }^{14}$

The National Veterinary Institute (NVI) of Ethiopia is producing live intermediate plus IBDV vaccine using LC75 strain using chicken embryo fibroblast cell (CEF). ${ }^{7}$ Production of IBD vaccine based on CEF cells needs high human labor for preparation of primary cell culture, costly since it needs use of SPF eggs and time-consuming with a minimum production capacity. Different cell lines such as Vero cells are also suitable for the growth of IBDV so that for vaccine production it is easily manageable and reproducible with a minimum cost but needs proper adaptation of the vaccine strain to the Vero cells.

Therefore, in this article we reported adaptation of IBDV vaccine strain (intermediate plus LC-75) on Vero cell, and evaluation of the safety, immunogenicity and efficacy of Vero cell adapted vaccine strain in the target host.

\section{Materials and Methods}

\section{Virus and Cell Culture}

IBD virus intermediate plus LC-75 vaccine strain was used for the Vero cell culture adaptation. A challenge field isolate IBD virus, NVI/MB/263/17, with infectious titre $\log 10^{5.3}$ $\mathrm{TCID}_{50} / \mathrm{mL}$ was used for assessing the protective potential of the vaccine. Vero cell, vaccine strain and challenge field virus isolate were obtained from the virology laboratory, Research and Development Directorate, NVI. Dulbecco's Modified Eagle's Medium (DMEM, HIMeDIA) with 10\% and $2 \%$ sterile fetal calf serum (FCS; Gibco) was used as a growth and maintenance medium for Vero cell culture, respectively. Media and solutions used for the growth of cells were Trypsin versene solution, phosphate buffered saline (PBS) and tryptose phosphate broth (TPB). Culture media were prepared aseptically according to the manufacturer's instruction (HIMeDIA).

\section{Adaptation of Vaccine Strain Using Vero Cells}

Vero cells were grown in $75 \mathrm{~cm}^{2}$ cell culture flask until confluent monolayer of cells was obtained. Confluent Vero cell monolayer was washed three times using prewarmed PBS $\mathrm{pH} 7.4$ to remove dead cells and suspended using pre-warmed $0.25 \%$ trypsin/EDTA solution under the Biosafety Cabinet Class II facility. Cell viability was checked with trypan blue stain and the number of viable cells was counted using cell counter $\mathrm{EVE}^{\mathrm{TM}}$ Automatic cell counter (E16041- 016, NanoEnTekInc, Korea). The viable cells were counted and seeded into $75 \mathrm{~cm}^{2}$ tissue culture flask containing pre-warmed DMEM (Sigma-Aldrich) supplemented with 10\% FCS (Gibco) at a seeding density of $2.1 \times 10^{6}$ cells. The cells were incubated and grown at $37^{\circ} \mathrm{C}$ with a humidified $5 \% \mathrm{CO}_{2}$ incubator. The cells were observed daily using an inverted microscope for the formation of confluent monolayer. ${ }^{15}$ 


\section{Infectious Bursal Disease Virus Inoculation into Vero Cell}

Confluent monolayer of Vero cells grown at $36 \mathrm{hrs}$ after sub-culturing was washed three times with pre-warmed sterile PBS and used for virus infection using adsorption method. The cells were infected by adding $0.5 \mathrm{~mL}$ of IBDV LC-75 vaccine strain with a multiplicity of infection (MOI) of $1: 100$ and incubated at $37^{\circ} \mathrm{C}$ for $1 \mathrm{hr}$ with intermittent tilting of the flask to allow virus adsorption. After $1 \mathrm{hr}$ incubation, $10 \mathrm{~mL}$ DMEM with $2 \%$ FCS was added into an infected flask and placed into $37^{\circ} \mathrm{C}$ incubator with $5 \%$ $\mathrm{CO}_{2}$. One flask of fresh cells with confluent monolayer was incubated as control under similar condition. The infected cells were observed daily for the development of virusinduced cytopathic effect (CPE) for six days. At six days of post-inoculation the infected cells with the virus were harvested, labeled and stored at $-80^{\circ} \mathrm{C}$ Ultra-Freezer. The harvested virus freeze-thawed alternatively three times at $-80^{\circ} \mathrm{C} /+30^{\circ} \mathrm{C}$ and inoculated to fresh monolayer of Vero cells. This process was repeatedly conducted up to passage 10 (P10) and decided to stop at this level to avoid occurrence of virus mutation. At each passage, the harvested flasks were labeled and kept at $-80^{\circ} \mathrm{C}$ until subsequent experiments.

\section{Titration of Infectious Bursal Disease Virus}

The viral suspension kept at $-80^{\circ} \mathrm{C}$ was diluted 10 -fold in sterile tubes $\left(10^{-1}\right.$ to $\left.10^{-10}\right)$ of passages $2,3,5,7,9$ and 10 . Then $100 \mu \mathrm{L}$ viral dilutions were dispensed into 96-Well Microplates (Thermo Scientific ${ }^{\mathrm{TM}}$ Nunc) containing $100 \mu \mathrm{L}$ Vero cells per well with 10 replicates for each dilution. Column 11 left empty and column 12 inoculated only with cells to serve as negative control. Finally, the plate was covered with plate cover and incubated at $37^{\circ} \mathrm{C}$ in $5 \% \mathrm{CO}_{2}$. The inoculated plates were monitored under inverted microscope daily starting from $72 \mathrm{hrs}$ post-inoculation for eight days. The titre of the virus at each virus passage was determined according to the Spearman Karber method. ${ }^{16}$

\section{Molecular Characterization of IBD Virus Adapted in Vero Cell}

The identity of the IBD virus vaccine strain adapted in Vero cell was checked by amplification of the viral hypervariable core protein (VP2) gene of the IBD virus using gene-specific primers by reverse transcription polymerase chain reaction (RT-PCR). ${ }^{17,18}$ Sequencing of the amplified
VP2 gene was conducted on vaccine working seed and from odd number passages $1,3,5,7,9$ and 10 to see if there is any nucleotide variation. The Wizard ${ }^{\circledR}$ SV Gel and PCR Clean-Up System (Promega, Germany) was used to purify the positive PCR products of the amplified VP2 gene. The NanoDrop 2000c spectrophotometer (Thermo Scientific, USA) was used to measure the DNA concentration of the purified PCR product. Concentration of each purified product was adjusted according to the instruction of the sequencing service provider company. The purified PCR product was mixed with the amplification/sequencing primers and submitted for sequencing to LGC Genomics (Berlin, Germany). The raw sequence data were analyzed using the bioinformatics software. Because of resource limitation it was difficult to do full genome sequencing.

\section{RNA Extraction, cDNA Synthesis and RT- PCR}

Virus RNA extracted from the harvested virus using the RNeasy ${ }^{\circledR}$ Mini Kit (Qiagen) following the manufacturer's instruction. The extracted RNA was subjected to two steps RT-PCR. A $10 \mu \mathrm{L}$ reaction mix was prepared from $3 \mu \mathrm{L}$ RNase free water, $1 \mu \mathrm{L}$ Oligo dT, and $1 \mu \mathrm{L}$ of $10 \mathrm{Mm}$ dNTP mix. Then, $5 \mu \mathrm{L}$ template RNA was added and incubated at $65^{\circ} \mathrm{C}$ for 5 minutes and placed at $4^{\circ} \mathrm{C}$. A $10 \mu \mathrm{L}$ volume for cDNA synthesis mix was prepared from $1 \mu \mathrm{L}$ DEPC treated water, $2 \mu \mathrm{L}$ of $1 \mathrm{X}$ RT buffer, $4 \mu \mathrm{L}$ of $25 \mathrm{mM} \mathrm{MgCl}$, $2 \mu \mathrm{L}$ of $0.1 \mathrm{MDTT}$, and $1 \mu \mathrm{L}$ superscript III-RT enzyme and incubated at $55^{\circ} \mathrm{C}$ for 50 minutes. The reactions were terminated at $85^{\circ} \mathrm{C}$ for 5 minutes and chilled on ice and then collected by brief centrifugation to which $1 \mu \mathrm{L}$ RNase was added per sample and incubated for 20 minutes at $37^{\circ}$ C. Finally, the obtained cDNA was immediately used for PCR. For running PCR, a total of $20 \mu \mathrm{L}$ master mix was prepared by using $3 \mu \mathrm{L}$ of RNase free water, $2 \mu \mathrm{L}$ of forward primer, $2 \mu \mathrm{L}$ of reverse primer, $10 \mu \mathrm{L}$ of $\mathrm{IQ}^{\mathrm{TM}}$ Supermix (Bio-Rad) and $3 \mu \mathrm{L}$ of template cDNA. The forward and reverse amplification primers used for the RT-PCR reaction to amplify the segment A, VP2 gene of the virus were used from the previously described method. ${ }^{19}$ The two primers are expected to amplify 729 base pairs of the VP2 gene. Master mix was prepared and amplified using touchdown PCR (thermal cycler 2720, applied Biosystems). The PCR cycles involved initial denaturation at $95^{\circ} \mathrm{C}$ for 5 minutes, followed by 15 cycles of denaturation at $95^{\circ} \mathrm{C}$ for $30 \mathrm{sec}$, annealing at $60^{\circ} \mathrm{C}$ for $30 \mathrm{sec}$, and elongation at $72^{\circ} \mathrm{C}$ for $30 \mathrm{sec}$. The 15 cycles of 
initial PCR followed by 20 cycles of denaturation at $95^{\circ} \mathrm{C}$ for $30 \mathrm{sec}$, annealing at $56^{\circ} \mathrm{C}$ for $30 \mathrm{sec}$, extension at $72^{\circ} \mathrm{C}$ for $30 \mathrm{sec}$ and final extension at $72^{\circ} \mathrm{C}$ for 7 minutes for 1 cycle. The amplified PCR products were stained with GelRed $^{\circledR}$ (Biotium) and visualized using 1.5\% agarose gel electrophoresis in $1 \times$ TAE buffer. A 100 bp DNA ladder (Fermentas) was used and IBD virus positive samples produced a PCR product of $729 \mathrm{bp}$ band size.

\section{Immunogenicity and Efficacy Tests}

A total of 80 14-day-old Koko breed SPF chicks of both sexes were used for the vaccine evaluation study. Chicks obtained from the Ethiopian Institute of Agricultural Research, Bishoftu center and screened for presence of maternal antibody against IBD virus using indirect Enzyme-linked immunosorbent assay (ELISA) test (IDvet, France) before commencing the animal experiment. All maternal antibody-free chicks aged 14 days were placed randomly into four groups (Group 1-4); the sample size (number of chicks) per group were 20 chicks (total 80 chicks) according to the OIE recommendation to be included in one experimental group. ${ }^{13}$ The chicks were managed under the animal experiment facilities of separated room for each treatment group with similar management to avoid any confounding factors among the different groups. Group 1 and 2 were inoculated with Vero cell adapted IBDV passage 5 and 10, respectively. Group 3 chicks were inoculated with Gumboro vaccine produced based on CEF cells, Batch number NVI-Gum 01/18, for comparison of immunogenicity test of Vero cell adapted IBDV, and group 4 served as negative control. At 18 days of age chicks were inoculated using ocular route with $1^{\wedge} 10^{5.4} \quad 50 \%$ Tissue Culture Infectivity Dose $\left(\mathrm{TCID}_{50} / \mathrm{mL}\right)$ antigen from passage 5, 10 and from CEF cell based IBDV vaccine batch (Gum 01/18) which was the product of the NVI, Bishoftu, Ethiopia. The chicks were boosted at day 14 post-inoculation. Blood samples were collected from all treatment groups on day 7, 14, 21 and 28 post-inoculation and subjected to indirect ELISA for antibody detection and titration. Efficacy test was conducted by inoculating challenge virus, using the field isolate vvIBD-VMB/263/17 with titre $\log 10^{5.3} \mathrm{TCID}_{50} / \mathrm{mL}$ dose $(0.2 \mathrm{~mL} / \mathrm{chick})$, to vaccinated and non-vaccinated control chicken groups on 21 days post-vaccination by inoculating through ocular route. ${ }^{20}$ The challenged chicks were observed for 10 days for any abnormalities, morbidity and mortality and the results were recorded as per OIE recommendation. ${ }^{13}$ The chicks were identified with a unique identification number attached to a wing and grouped and followed up blindly for data analysis.

\section{Indirect ELISA}

An indirect ELISA test was conducted at the Immunology laboratory of the NVI following the manufacturers' instruction (IDvet, France). Optical density (OD) of the test sample was measured using the microtiter plate reader (Thermo Fisher Scientific MULTISKAN MCC) at 450nm absorbance. The percentage positivity for test samples in relation to the negative and the positive controls was calculated as per the formula given by the ELISA kit manufacturer. The result was interpreted with reference to the cut-off value recommended by the manufacturer as the $\mathrm{OD}_{\mathrm{PC}}$ (positive control) should be $>0.25$, and $\mathrm{OD}_{\mathrm{PC}} /$ $\mathrm{OD}_{\mathrm{NC}}$ should be $>3.0$; formula indicated at the data management section.

\section{Animal Management}

All experimental chicks were handled following to the NVI Animal Handling and Research Ethics Guideline. Formulated feed and water were provided ad libitum. After the end of the experiment, the chicks were euthanized humanly using manual cervical dislocation involved stretching and separating the cervical vertebrae by hand and properly incinerated using the incinerator located inside the institute compound considering all the biosafety and biosecurity measures. Approval of animal experiment ethical clearance was obtained from the Animal Research Ethical Review Committee, College of Veterinary Medicine and Agriculture, Addis Ababa University, Ethiopia with the certificate Reference Number: AAU/ CVMA/VM/ERC/28/05/10/2018.

\section{Data Management and Statistical Analysis}

All the collected data were entered into Microsoft Excel spread sheet program and analyzed using STATA version 12. ${ }^{21}$ A one-way analysis of variance (ANOVA) was used to differentiate effect of passage levels on immunogenicity of vaccines in chicks. Statistical significance was based on $p<0.05$. The formula used for calculation of sample antibody level was taken from the kit manufacturer as described below.

$$
\mathrm{SP} \text { value }=\mathrm{OD}_{\text {sample }}-\mathrm{OD}_{\mathrm{NC} /} \mathrm{OD}_{\mathrm{PC}}-\mathrm{OD}_{\mathrm{NC}}
$$

Where; SP: sample to positive ratio, OD: optical density, $\mathrm{NC}$ : negative control, PC: positive control. 


\section{Results}

\section{Adaptation of IBDV LC-75 on Vero Cells}

The result of the present study showed that the LC-75 strain of IBDV vaccine strain successfully adapted in Vero cell culture starting from passage 2. At the first passage, the infected cells remained intact on the surface of tissue culture flask and did not show any CPEs formation. During second passage, CPEs were observed starting from day 4 post-inoculation. However, starting from passage 3 up to passage 10, visible CPEs happened at day 3 post-infection by observing typical aggregation, rounding and clumping of large number of cells and detachment of infected cells with few cells floating in media as visualized by inverted microscope (Figure 1).

\section{Titration of IBDV}

The infectivity of adapted IBDV LC-75 to Vero cells was determined by calculating 50\% endpoint as described by Spearman Karber method (Ramakrishnan, 2016). The total infectious virus $\log _{10} \mathrm{TCID}_{50} / \mathrm{mL}$ titer of Vero cell adapted passage 2, 3, 5, 7, 9 and 10 were 5.4, 5.60, 5.9,6 and 6.2, respectively (Figure 2). The best-fit equation for the $\log$ titer increment was $\mathrm{Y}=5.0695+0.1104 \mathrm{x}$ (" $\mathrm{x}$ " stands for passage number).

\section{Molecular Detection and Sequencing}

The amplified PCR products were visualized on agarose gel electrophoresis that resulted in the generation of $729 \mathrm{bp}$ expected size amplicon of the VP2 gene (Figure 3). PCR amplicons obtained from virus-infected Vero cell homogenates were confirmed as IBDV (Figure 3). The VP2 gene nucleotide sequences of the present LC-75 vaccine strain virus isolated from the different culture passages were analysed and cleaned sequences were deposited in the GenBank with accession numbers of IBDV/LC-75/passage 1 (MK798159), IBDV/LC-75/passage 5 (MK798160) and IBDV/LC-75/passage 10 (MK798161).

\section{Immunogenicity of the Developed Vaccine}

The indirect ELISA test result showed that all chicks revealed a small amount of the maternally-derived antibody that is within the negative range of the $\mathrm{S} / \mathrm{P}$ ratio. Seven days post-inoculation of the antigen, the mean S/P ratio for Group 1 inoculated from passage 5 was 0.046
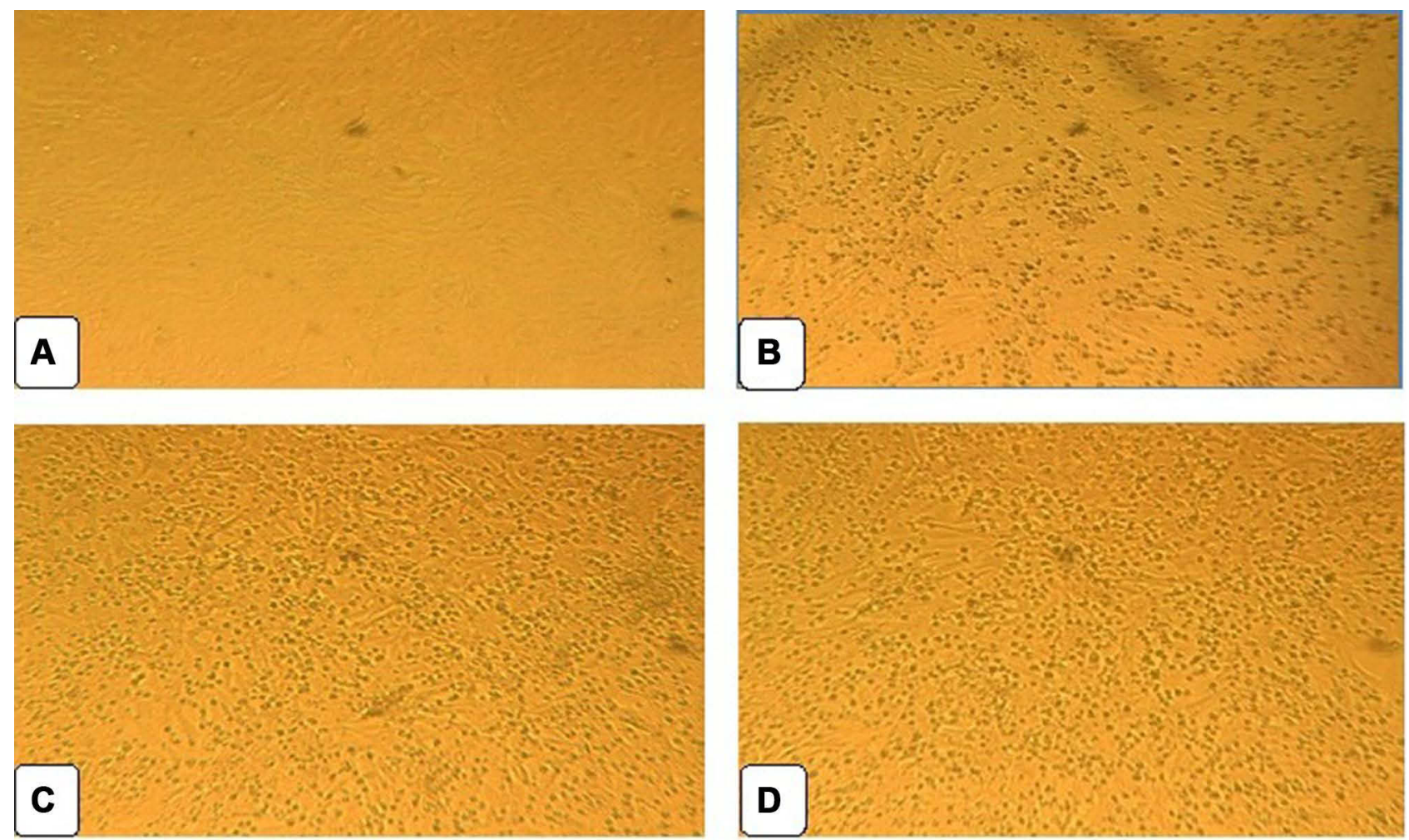

Figure I CPE observed on Vero cell culture infected at different passages of IBDV LC-75 vaccine strain using Inverted microscope $(\times 40)$. Where; $($ A) Vero cell control, and observation of CPE were recorded at (B) passage 5, (C) passage 7, and (D) passage 9. 


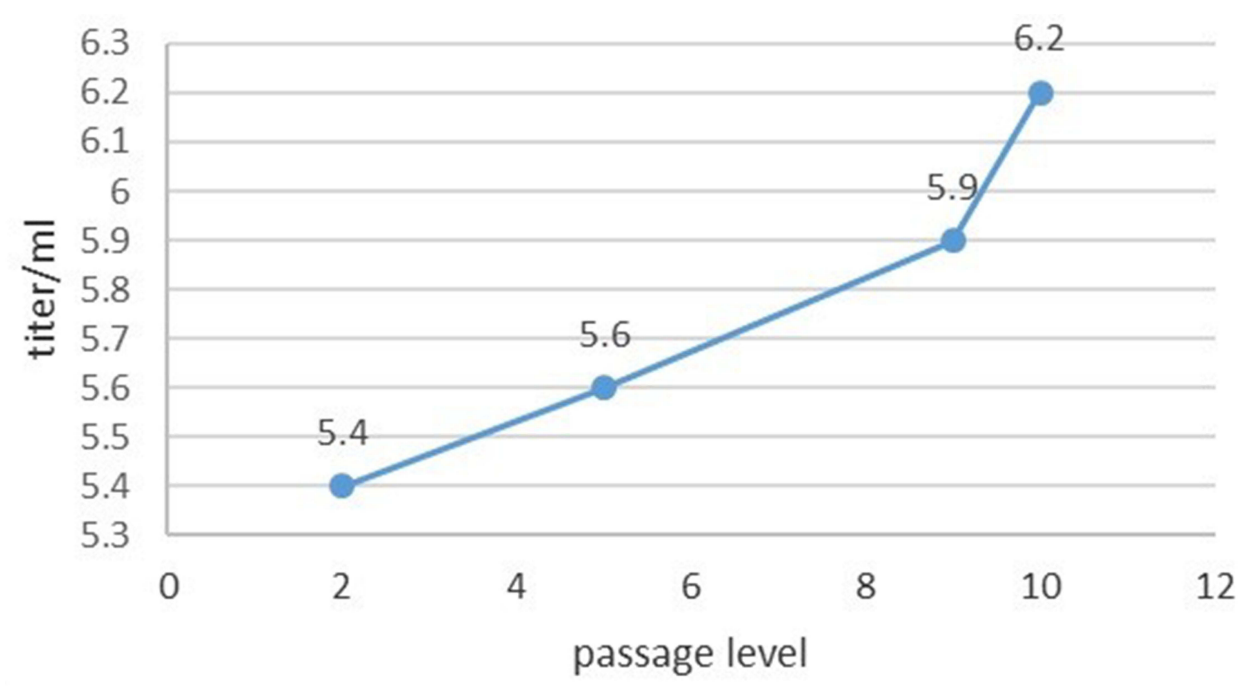

Figure 2 Vero cell adapted IBD virus titration result at different passage number.

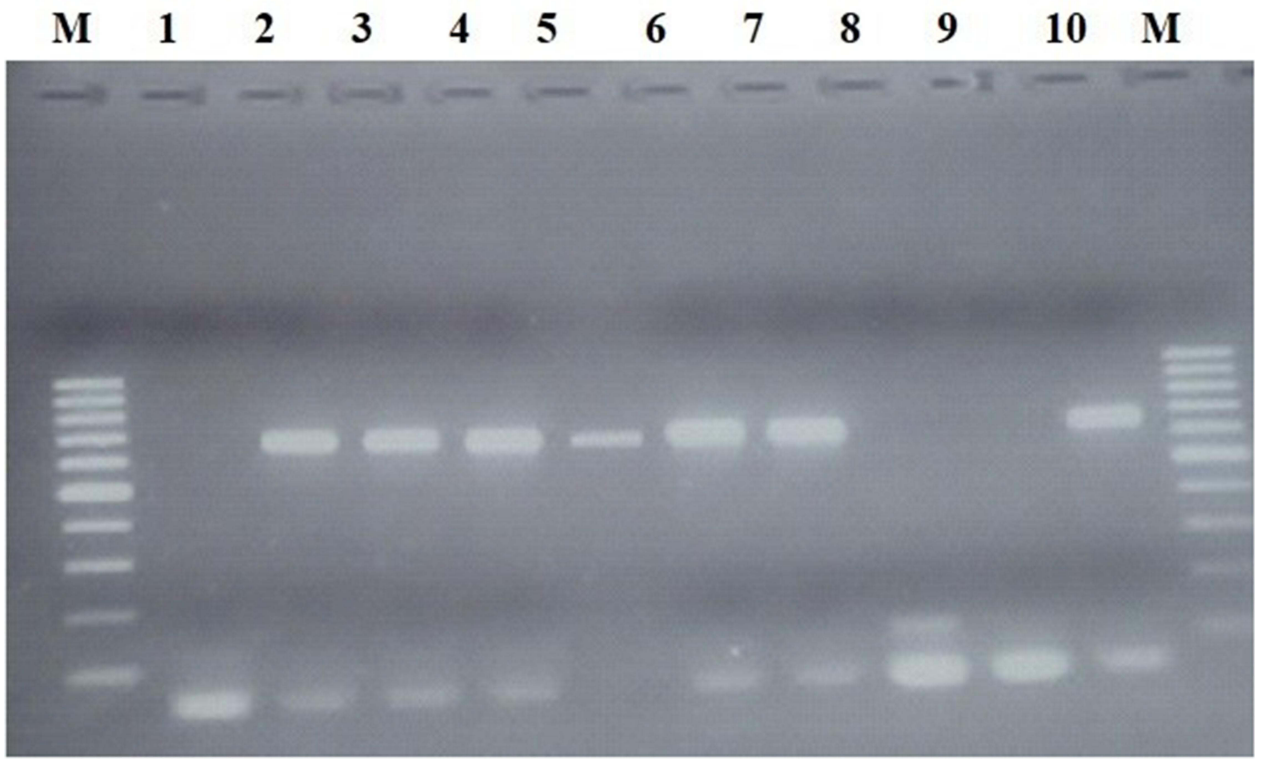

Figure 3 Agarose gel electrophoresis picture showing the 729 bp fragment of the IBDV VP2 gene. Where; (M) Molecular ladder (I00bp, Fermentas), (I) Vero cell control (Negative), (2) Original culture (Positive), (3) Vero cell culture passage 5, (4) Vero cell culture passage 6, (5) Vero cell culture passage 7, (6) Vero cell culture passage 8, (7) Vero cell culture passage 9, (8) Extraction control (RNA free water), (9) Negative control, and (10) Positive control.

(antibody titer 141.86), for Group 2 inoculated from passage 10 was 0.068 (antibody titer 207.27) and for Group 3 inoculated with CEF cell-based vaccine was 0.094 (antibody titer 283.75). At day 14 post-inoculation $\mathrm{S} / \mathrm{P}$ ratio was 1.28 (antibody titer 3572.68) for passage 5, 1.53 (antibody titer 4247.67) for passage 10 and 1.76 (antibody titer 4865.72) for CEF based vaccine (Gum 01/18). At day 21 post infections the S/P ratio or antibody titer seems equal with that of day 14 post-inoculation (Figure 4). The chickens were boosted at day 14 post-inoculation and, after
7-14 day of boosting, the S/P ratio was strongly increased from 1.53 (antibody titer 4247.67) to 2.15 (antibody titer 6307.77) (Figure 4).

\section{Immunogenicity and Efficacy Evaluation}

The comparison of immunogenicity evaluation of the IBD virus antibodies produced against Vero cell adapted virus from passages 5 and 10 with that of CEF cell based NVI vaccine (Batch Gum 01/18) showed the absence of significant difference between the two IBD vaccines used $(p>0.05)$. 


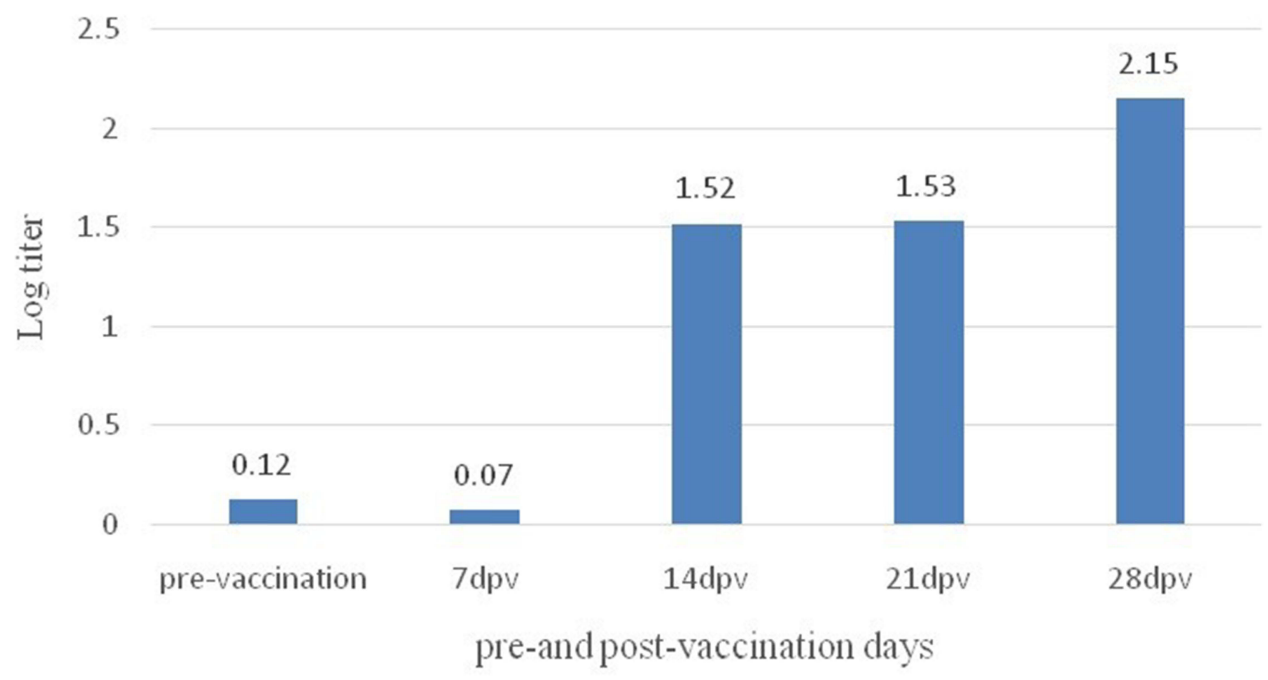

Figure 4 Mean S/P ratio of specific IBDV antibody measured at pre-vaccination (day 0, before vaccination) and post-vaccination (different days of interval after vaccination). Abbreviation: $\mathrm{dpv}$, days post-vaccination.

Chick vaccinated with Vero cell adapted LC-75 IBDV strain from passages 5 and 10 and from CEF cell based vaccine (Batch Gum 01/18) was found to be safe after challenge/ pathogenicity with virulent field isolates since no observed abnormalities, clinical signs and death as compared to the unvaccinated control group (Figure 5). Starting from day 4 post-inoculations with challenge virus, $60 \%$ of chicks from control (unvaccinated) group showed clinical signs such as ruffled feather, inappetence, difficult movement, yellowish diarrhea and dehydration, while $25 \%$ of the unvaccinated chickens died starting from day 6 post-challenge.

\section{Discussion}

The CEF cell-based vaccine production needs SPF chicken eggs, nevertheless obtaining of SPF eggs needs foreign currency for importation from Europe and processing of the embryo for cell culture preparation requires additional labor cost as its processing is labor-intensive and cannot be easily scaled up for large scale vaccine production. The use of Vero cell culture for IBDV vaccine production could be the best alternative.

In the present study, IBDV LC-75 vaccine strain was successfully adapted in Vero cells and the virus titer was compared with the IBD vaccine produced using CEF cells using the same vaccine strain. The Vero cell adapted IBDV LC-75 vaccine strain at different passages were proved to be immunogenic and protected chickens against challenge with vvIBDV field strain (MB/263/17). Hence, the Vero cell based IBDV vaccine is recommended for large scale vaccine production in Ethiopia. Previous study suggested that the use of

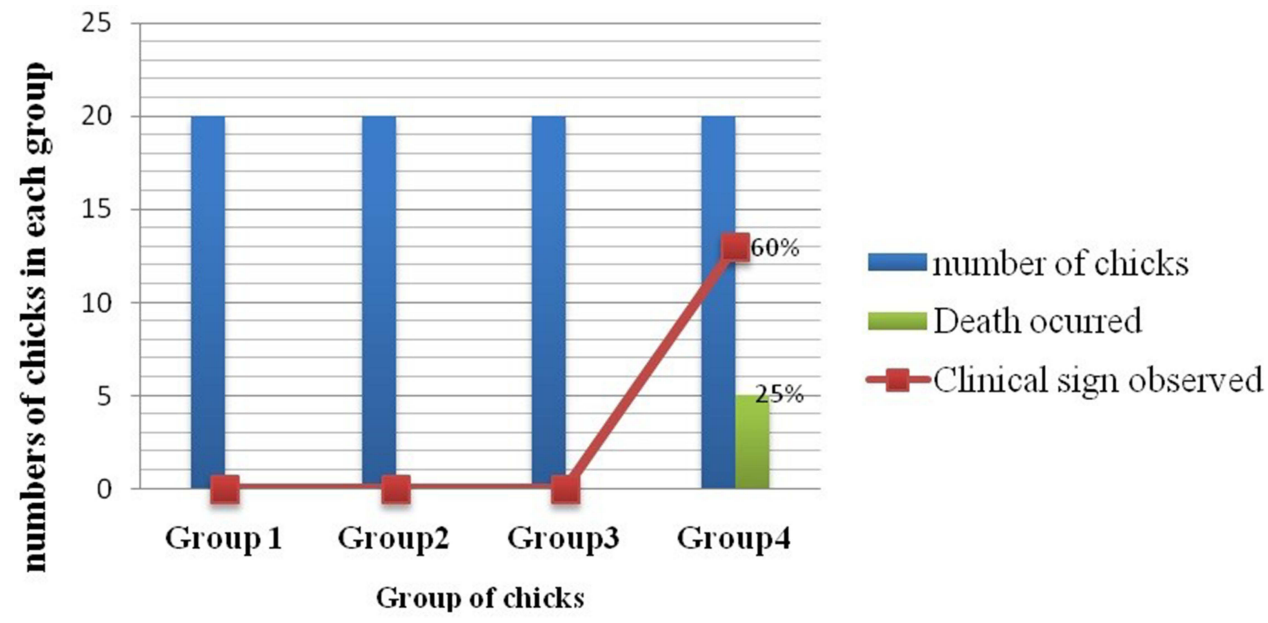

Figure 5 Percentage of clinical sign and death observed in chicken vaccinated with different vaccine passages and challenged with vvlBDV. 
Vero cells in growing avian viruses could become an economical, less laborious, and continuous and efficient tool with an advantage of measuring virus effects outside the host animal as compared to the laborious preparation of primary $\mathrm{CEF}$ cell. ${ }^{22}$ We have tested that confluent monolayer of Vero cells, following $36 \mathrm{hrs}$ of sub-culturing in growth medium, infected with IBDV LC-75 remained fully intact in passage 1 (P1) up to six days post-infection. The infected cells of the first passage was blindly harvested and passaged to the next (second passage or P2), some changes in Vero cell monolayer began to develop on fourth day of incubation. The monolayer showed rounding of infected cells; however, complete CPEs of the Vero cells were not observed in this passage. CPE was observed starting from day-three post-infection after the virus became adapted to the cell culture. This explained that the virus adapted itself onto the Vero cell culture and started replication well and revealed observed CPEs. The passage level and the time at which the CPE observed and completed in the present study was similar to the previous report. ${ }^{15} \mathrm{On}$ the other hand, detection of IBD virus titer inoculated on Vero cell was not observed and this could be related to the strain of the IBD virus or passage level used. ${ }^{23}$

The current study result also indicated presence of difference in time of CPEs observation with that of Silva et al that reported IBDV CPEs in Vero cells at $18 \mathrm{hrs}$ postinfection. $^{24}$ The titer of Vero cell adapted IBDV LC-75 strain increased with passage number starting from passage 3 indicating that the vaccine strain is well adapted to Vero cell environment and the virus replicates successfully to high titer as shown in Figure 2. The figure shows that as the passage number increases, the titer of the virus also increases linearly. For example, in passage 3, the vaccine strain had a titer of $\log _{10} 5.40 \mathrm{TCID}_{50} / \mathrm{mL}$. According to Code of American Federal Regulation, IBD vaccine strain titer must not be less than $\log _{10}{ }^{3.40} \mathrm{TCID}_{50} /$ dose and the current titer $\left(\log _{10} 5.40 \mathrm{TCID}_{50} / \mathrm{mL}\right)$ is higher than recommended by Code of American Federal Regulation (2012) for protecting chickens against the disease. ${ }^{25}$ This suggests that the 3rd passage could be used as a vaccine to protect the chicken against vvIBDV. Similar findings in growth pattern of vvIBDV in Vero cells at passage 3 after $72 \mathrm{hrs}$ of infection was reported. ${ }^{15}$ To confirm identity of the Vero-cell adapted IBDV LC-75 vaccine strain, RT-PCR test conducted amplifying the VP2 region. As expected, we amplified and sequenced the expected $729 \mathrm{bp}$ band of the VP2 gene fragment. Sequencing of the VP2 gene was recommended for checking absence of nucleotide and/or amino acid variations since the VP2 gene is responsible for the antigenicity, antigenic variation, and pathogenicity of the IBD virus. ${ }^{1,26,27}$

Immune response status of the chicks following vaccination was assessed using indirect ELISA at 7 days post-inoculation, and all groups of chickens had contained antibody titer less than positive range $(>0.3)$ suggesting that the vaccine might not provide sufficient protection within a week. Starting from day 7 up to day 14 post-inoculation, all groups of chickens inoculated with both Vero cells adapted virus and NVI-Gum 01/18 vaccine had increased antibody titer from 213.18 to 4220.74 or S/P (0.07 to 1.52$)$. The mean antibody produced at day 14 post inoculations were closely similar with day 21 post-inoculation (7 days post-boost, Figure 4) suggesting as the maximum immune response was achieved but the exact day on which maximum immune response was achieved need to be determined by sampling the animals between days 14 and 21 and after 21 day. A similar idea was reported that the antibody titer at 14 days of post-infection resulted in a gradual increase of antibody values in all inoculated groups. ${ }^{28}$ This result also agreed with the previous report about immunity reaction to "intermediate plus" or "hot" vaccine of IBDV that the intermediate plus vaccineinduced antibody levels already at 14 days post-vaccination.${ }^{29}$ The mean S/P ratio was highly increased starting from day 21 post-inoculation. Since chickens in all groups were booster vaccinated at day 14 post-inoculation, antibody production was enhanced and mean S/P ratio or the antibody titer increased. In all forms of vaccination group, there was no significant difference $(p>0.05)$ in vaccine-induced antibody production.

Hence Vero cell adapted IBDV vaccine strain is equally immunogenic at passages 5 and 10 with that of chicken fibroblast cell-based prepared vaccine. Upon comparative evaluation of the efficacy of the Vero cell adapted and CEF cell based vaccine against challenge with local virulent field strain of vvIBDV, chickens vaccinated by the two cell-type based vaccines were fully protected with no recorded morbidity and mortality. The challenged control chickens (unvaccinated groups) responded by high morbidity and mortality rate starting from 3rd day post-challenge. There were clinical manifestations of anorexia, ruffling of feathers and death on day 6 post-infection; nonetheless no clinical sign and death occurred in all the vaccinated chickens. Therefore, Vero cell adapted LC-75 IBD virus vaccine is efficacious to protect the chicken against the circulating field vvIBDV similar to that of CFC based prepared vaccine as described previously. ${ }^{13}$ 


\section{Conclusion}

The present study confirmed that Vero cell adapted attenuated IBDV vaccine could be successfully produced similar with that of the CEF cell vaccine. The IBDV vaccine strain LC-75 adapted well onto Vero cells as early as passage 3 with a good virus titer. The adapted vaccine is equally immunogenic and efficacious with no difference between passages and with CEF cells based prepared vaccine. It is more economical to produce IBDV vaccine in large scale using Vero cell culture. Based on the above conclusion remarks, production of IBD vaccine using Vero cell line is recommended. In the future, a closely host related cell type like avian stem cells or cell line developed from chicken origin could replace Vero cells and CEF cells for better vaccine production for the protection of IBD virus and other avian pathogens as it allows use of host-related cell type for vaccine production that overcomes virus adaptation problem and also facilitates better vaccine production at the industrial scale.

\section{Acknowledgments}

We would like to thank the NVI for giving the chance for the first author to pursue his postgraduate study and allow him to conduct the research in the institute facilities. Mrs Wubet W/Medhin, Mr Abenet Legesse and Mr Alebachew Belay are appreciated for the technical assistance during laboratory assays. The Animal Production and Health subprogram of the IAEA, Vienna, Austria is highly acknowledged for supporting the sequencing service through Member States supporting program.

\section{Funding}

The research was funded by the National Veterinary Institute (NVI) by providing the laboratory facilities, reagents, consumables and animal experiment rooms. The Ministry of Innovation and Technology (MInT) of Ethiopia financially supported the research activities through the project "Development of a novel immuno prophylaxis for Infectious Bursal Disease and Fowl cholera from local isolates". The funding bodies had no role in the design of the study, sample collection, statistical analysis and interpretation and writing of the manuscript.

\section{Disclosure}

The authors report no conflicts of interest in this work.

\section{References}

1. Brandt M, Yao K, Liu M, et al. Molecular determinants of virulence, cell tropism, and pathogenic phenotype of infectious bursal disease virus. J Virol. 2001;75:11974-11982. doi:10.1128/JVI.75.24.1197411982.2001

2. Delmas B, Attoui H, Ghosh S, et al. ICTV report consortium. ICTV virus taxonomy profile. Birnaviridae J Gen Virol. 2019;100:5-6. doi:10.1099/jgv.0.001185

3. Central Statistical Authority (CSA). Federal Democratic Republic of Ethiopia. Central Statistical Authority. Agricultural Sample Survey. Report on Livestock and Livestock Characteristics. Vol. II. Statistical Bulletin 589, Addis Ababa, Ethiopia; March 20, 2019.

4. Zeleke A, Yami M, Kebede F, et al. An emerging disease threat to poultry Debre Zeit. Ethiop Vet J. 2002;6:1-7.

5. Zeleke A, Gelaye E, Sori T, et al. Investigation of infectious bursal disease outbreak in Debre Zeit. Int J Poult Sci. 2005;7:504-506.

6. Jenbere S, Lynch SE, Kebede F, et al. Genetic characterization of infectious bursal disease virus isolates in Ethiopia. Acta Trop. 2014;130:39-43. doi:10.1016/j.actatropica.2013.09.025

7. Mekuriaw A, Bitew M, Gelaye E, et al. Infectious bursal disease: outbreak investigation, molecular characterization, and vaccine immunogenicity trial in Ethiopia. Trop Anim Health Prod. 2017;49:1295. doi:10.1007/s11250-017-1328-2

8. Tadelle D, Ogle B. Village poultry production systems in the central highlands of Ethiopia. Trop Anim Health Prod. 2001;33:521-537. doi:10.1023/A:1012740832558

9. Mardassi H, Khabouchi N, Ghram A, et al. A very virulent genotypes of infectious bursal disease virus predominantly associated with recurrent infectious bursal disease outbreaks in Tunisian vaccinated flocks. Avian Dis. 2004;48:829-840. doi:10.1637/7210-052004R

10. Samson T. Infectious bursal disease: an important challenge in transforming the Ethiopian poultry sector. Greener J Agri Sci. 2018;10:277-285.

11. Eterradossi N, Saif YM. Infectious bursal disease. In: Diseases of Poultry. 12th ed. Ames: Iowa State University Press; 2008:185-188.

12. Camilotti E, Moraes LB, Furian TQ, et al. Infectious bursal disease: pathogenicity and immunogenicity of vaccines. Braz J Poult Sci. 2016;18:303-308. doi:10.1590/1806-9061-2015-0148

13. OIE. Infectious Bursal Disease (Gumboro Disease); Version Adopted by the World Assembly of Delegates of the OIE; 2016.

14. Van den Berg TP, Gonze M, Meulemans G. Acute infectious bursal disease in poultry: isolation and characterization of a highly virulent strain. Avian Pathol. 1991;20:133-143. doi:10.1080/ 03079459108418748

15. Hussain I, Rasool MH. Adaptation of an indigenous very virulent infectious bursal disease virus on Vero cell line. Pak Vet J. 2005;25:103-106.

16. Ramakrishnan M. Determination of $50 \%$ endpoint titer using a simple formula. World J Virol. 2016;5:85-86. doi:10.5501/wjv.v5.i2.85

17. Jackwood DJ. Recent trends in the molecular diagnosis of infectious bursal disease viruses. Anim Health Res Rev. 2004;5:313-316.

18. Mosad SM, Eladl AH, El-Tholoth M, et al. Molecular characterization and pathogenicity of very virulent infectious bursal disease virus isolated from naturally infected Turkey poults in Egypt. Trop Anim Health Prod. 2020;52(6):3819-3831. doi:10.1007/s11250-02002420-5

19. Office of International des Epizooties. Manual of diagnostic tests and vaccines for terrestrial animals. Infect Bursal Dis. 2012; chap. 2.3.12:549-565.

20. El-Bagoury GF, Nada AF, El-Sayed El-Habbaa AS, et al. Evaluation of an inactivated infectious bursal disease virus vaccine prepared using a local isolate from Egypt, Bonham. Vet Med J. 2015;28:67-77.

21. Stata Corp. Stata Statistical Software: Release 12 College Station. TX: Stata Corp LP; 2011. 
22. Ahmed H, Mostafa S, Elrefaie R, et al. Growth of different infectious bursal disease virus strains in cell lines from origin of lymphoid leukosis tumors. Anim Vet Sci. 2015;3:46-50. doi:10.11648/j. avs.20150302.13

23. Isabela CS, Maria JB, Fernandes RMC, et al. Susceptibility of cell lines to avian viruses. Rev Microbiol. 1999;30:373-376. doi:10.1590/ S0001-37141999000400015

24. Silva SEL, Ferreira HL, Carvalho BA, et al. Cardoso susceptibility of mammalian cell line for isolation of IBDV from clinical samples. Braz J Poult Sci. 2004;6(1):65-69. doi:10.1590/S1516635X2004000100009

25. CFR (Code of American Federal Regulation-13CFR) USA. Office of the Federal Register National Archives Records Service, Animals and Animal Products. Ch.1 11.30. 2012:113-133.
26. Jackwood DJ, Sommer-Wagner SE. Amino acids contributing to antigenic drift in the infectious bursal disease Birnavirus (IBDV). Virology. 2011;409(1):33-37. doi:10.1016/j.virol.2010.09.030

27. Jackwood DH, Saif YM. Antigenic diversity of infectious bursal disease viruses. Avian Dis. 1987;31:766-770. doi:10.2307/1591028

28. Ahmad AN, Iftikhar H, Masood A, et al. Comparative study of commercially available infectious bursal disease vaccine with egg attenuated live vaccine. Pak J Zool. 2014;46:959-966.

29. Rautenschlein S, Kraemer C, Vanmarcke J, et al. Protective efficacy of intermediate and intermediate plus infectious bursal disease virus (IBDV) vaccines against very virulent IBDV in commercial broilers. Avian Dis. 2005;49:231-237. doi:10.1637/7310-112204R

\section{Publish your work in this journal}

Veterinary Medicine: Research and Reports is an international, peerreviewed, open access journal publishing original research, case reports, editorials, reviews and commentaries on all areas of veterinary medicine. The manuscript management system is completely online and includes a very quick and fair peer-review system. Visit http://www.dovepress.com/testimonials.php to read real quotes from published authors. 